\title{
Effects of free-range and confined housing on joint health in a herd of fattening pigs
}

\author{
Pernille Engelsen Etterlin ${ }^{1 *}$, Bjørnar Ytrehus ${ }^{2}$, Nils Lundeheim³ ${ }^{3}$ Eva Heldmer ${ }^{4}$, Julia Österberg ${ }^{5}$ and Stina Ekman ${ }^{1}$
}

\begin{abstract}
Background: Free-range housing, in which pigs have access to both indoor and outdoor areas, is mandatory in organic pig production in Europe, but little is known about the effects of this housing on joint health in pigs. A high level of joint condemnations at slaughter has been reported in organic free-range pigs in Sweden, compared with pigs raised in conventional confined housing. We hypothesised that biomechanical forces imposed on the joints of pigs that range freely promote the development of osteochondrosis and lead to joint condemnation. We compared the prevalence of osteochondrosis and other joint lesions (e.g. arthritis, traumatic) in the elbow and hock joints of 91 crossbred Hampshire (Yorkshire $\times$ Landrace) fattening pigs that were housed in a free-range indoor/outdoor system with that in 45 pigs housed in confined indoor pens.

Results: A larger proportion of free-range than confined pigs had osteochondrosis in the elbow joints (69 vs. 50\%, $p<0.05$ ), and a higher proportion of these joints in free-range pigs showed moderate or severe lesions ( $33 \mathrm{vs.} 16 \%$, $p<0.05$ ). The free-range pigs also showed a higher prevalence of osteochondrosis in the hock joints (83 vs. $62 \%$, $p<0.05)$ and a larger proportion of these joints had moderate or severe lesions ( $69 \mathrm{vs.} \mathrm{33 \% ,} p<0.001$ ). At slaughter, $4.2 \%$ of the free-range pigs had condemned joints, all of which showed severe osteochondrosis, while no joints of confined pigs were condemned.

Conclusions: In this experiment the prevalence of osteochondrosis in the elbow and the hock was higher, and lesions were more severe, in free-range than in confined pigs, suggesting that free-range housing increases the risk of acquiring osteochondrosis. Increased biomechanical stress to vulnerable joint structures may be the mechanism behind this effect, however more studies are needed to verify these results. This study suggests that modification of housing, and breeding for joints that are more adapted to free-range movement may be needed in free-range pig production. Severe osteochondrosis is a cause of joint condemnation, but the condemnation rate at slaughter underestimates the actual frequency of joint lesions and hence is a poor assessment of joint health.
\end{abstract}

Keywords: Pigs, Housing, Organic, Free-range, Joints, Osteochondrosis, Elbow, Hock

\section{Background}

The number of organic fattening pigs slaughtered in Sweden rose from 3,000 in 1997 to 31,260 in 2012 [1]. The number of joints rejected at slaughter has also been rising. Meat inspection statistics collected by the Swedish Animal Health Service (SvDHV) over the last 16 years show that joints from 2.5 to $6.5 \%$ of all organic fattening pigs, compared to 1 to $2.2 \%$ of all joints from conventional pigs, are condemned at slaughter.

\footnotetext{
* Correspondence: pernille.etterlin@slu.se

'Section of Pathology, Department of Biomedical Sciences and Veterinary Public Health, Swedish University of Agricultural Sciences (SLU), 75007 Uppsala, Sweden

Full list of author information is available at the end of the article
}

Previous studies on organic fattening pigs in Sweden indicate that osteochondrosis [2] and infectious conditions, mainly arthritis caused by Erysipelothrix rhusiopathiae [3], are the causes of lesions in the majority of condemned joints. However, there is a dearth of information on the normal health status of joints of fattening pigs in organic production. Joint condemnation rates are often mentioned in research and discussions on health in organic pigs [3-11], but it is unknown how well joint rejections at slaughter reflect the actual frequency of lesions in the joints of fattening pigs.

Osteochondrosis (OC), defined as a local disturbance in the process of endochondral ossification [12], occurs in all common pig breeds [13] and is an important cause 
of leg weakness and joint illness [14-17]. The primary lesions are ischemic necroses of growth cartilage due to premature cessation of the cartilage canal blood supply [18]. Lesions range from clinically silent, microscopic changes called osteochondrosis latens, to macroscopically visible retained cartilage called osteochondrosis manifesta, to osteochondrosis dissecans (OCD) [18-20], in which clefts form between the articular surface and the subchondral bone, causing joint inflammation $[16,18,21,22]$. Heredity, anatomical features, rapid growth, and nutrition are some of the most commonly discussed etiologies of OC $[16,18]$. Increased biomechanical stress and/or trauma have also been proposed as factors in the formation of primary lesions and the successive stages of OC [22-26].

A key characteristic of organic pig production is an enriched environment that includes a large space, free access to an outdoor paddock and/or pasture, deep straw bedding, and large group housing, all of which together provide a more 'natural' habitat for the pigs. Allowing pigs to range freely enables them to engage in various exploratory activities and exercise. Such an increase in activity presumably increases the magnitude and the diversity of biomechanical forces exerted on the joint structures. These forces may lead to increased incidence of microtrauma that causes failure of the cartilage canal blood supply and initiates the formation of osteochondrosis latens lesions, and to the progression of a manifest lesion to osteochondrosis dissecans, affecting both the prevalence and the severity of lesions.

The aim of this study was to describe the joint lesions and examine their frequency, and to compare the prevalence and severity of $\mathrm{OC}$ in fattening pigs raised in a freerange environment or a confined system located on the same farm. Furthermore, we suspected that conventional meat inspection fails to identify all joints with severe pathological lesions and we compared the condemnation rate with the true prevalence of lesions in two commonly affected joints.

\section{Methods}

This study was approved by the Gothenburg Ethical Committee on Animal Research and was performed in the summer and autumn of 2012.

\section{Animals and housing}

The study included 150 crossbred (offspring of Landrace $\times$ Yorkshire sows, inseminated with Hampshire semen) pigs born in the same week in one piglet-producing herd in Sweden, managed according to the European Union organic regulations on organic farming [27]. Piglets were housed with their sows in individual standard indoor Swedish farrowing pens $\left(6 \mathrm{~m}^{2}\right)$ until 2 weeks of age. The sows and their litters were then placed in two large adjacent group pens with deep straw bedding, from which they had access to an outdoor run with a concrete floor. After the piglets were weaned at approximately 7 weeks of age, the sows were removed from the pens. When they were twelve weeks old, 150 piglets were selected at random from these two pens and ear-tagged with identification numbers in both ears. The marked individuals were transported $160 \mathrm{~km}$ by truck to a commercial organic fattening farm in Sweden and subdivided into two different housing systems.

Fifty pigs were first unloaded and placed in confined indoor housing, in which five to seven pigs shared each $12-\mathrm{m}^{2}$ pen. The pens had solid concrete floors, minimal bedding in the resting area, and a slatted concrete floor in the defecation area. The remaining 100 pigs were randomly sorted into two groups of 50 in a separate building and housed in two identical neighboring pens that complied with the EU regulations on organic farming [27]. Each pen had a $90-\mathrm{m}^{2}$ indoor area that included a feeding area with a solid concrete floor, a resting area with deep $(0.5 \mathrm{~m})$ straw bedding, and a defecation area with a slatted concrete floor. The outdoor area consisted of a run with a concrete floor $\left(26 \mathrm{~m}^{2}\right)$ and access to pasture (approximately $2500 \mathrm{~m}^{2}$ ), as required by KRAV, the Swedish organic certification organisation [28]. The original experimental design called for only one of the two free-range pens to have access to the pasture. However, the barriers between the free-range pens were inadequate; the pigs intermingled from the first day and were thus considered as a single experimental group.

All pigs were provided water ad libitum and received the same feed. Pigs were fed three times each day in a feeding trough. The type and the amount of feed followed the specifications of the Swedish University of Agricultural Sciences (SLU) feeding norm [29] and the standards in the EU regulations on organic farming [27]. The pigs were fed almost ad libitum until they reached $60 \mathrm{~kg}$ average live weight, after which they received the average equivalent of 34 MJ per pig each day until slaughter. The farmer inspected the animals' health daily, and we examined each pig individually on three separate occasions. Slaughter-ready pigs (5.5-6.5 months, approximately $100-110 \mathrm{~kg}$ live weight) from all housing groups were culled weekly and transported together $187 \mathrm{~km}$ to a large commercial slaughterhouse. Pigs that were euthanised because of clinical illness, lost their identification tags, or reached slaughter weight after 7 months of age were excluded from the study.

A pilot study on condemned joints in organic fattening pigs [2] showed that the hock and elbow joints were the most commonly affected. Therefore, our investigation focused on lesions in these two joints. After slaughter, all elbow and hock joints of all legs, including joints from condemned limbs, were collected unopened. The joints were separately packed, labelled and transported 
in refrigerator trucks to SLU in Uppsala, where they were frozen at $-20^{\circ} \mathrm{C}$ until further analysis.

\section{Post-mortem examination}

The joints were thawed, sampled, and examined at room temperature. Joints were opened using sterile techniques and the synovial fluid and membranes were assessed macroscopically for signs of inflammation. When joints showed discolouration, increased quantities of synovial fluid, or hyperemia or thickening/proliferation of the synovial membrane, samples were taken from three separate, standardised areas of the synovial membrane and immersed in $10 \%$ neutral buffered formalin. In addition, samples of synovial membrane were frozen for later research. The formalin-fixed synovial membranes were embedded in paraffin, dehydrated, cut into $3-\mu \mathrm{m}$ sections, and stained with haematoxylin and eosin and examined histologically. Selected slides were Gram-stained.

The tissues surrounding the articulated bones were completely removed and the joint capsule was incised, separating the two bones. Assessment of pathological lesions was performed by the first author without knowledge of the identity or group allocation of the individual animals. The articular surfaces (distal humerus, proximal radius, proximal ulna, distal tibia, distal fibula, proximal and distal talus and calcaneus) and the intra-articular ligaments were subsequently inspected for lesions (ruptures, fractures, haemorrhages, or inflammation).

An initial examination of the presence or absence of OC, recognized as cleft formation, focal irregularity or whitening/thickening of the cartilage, was performed on all intact articular surfaces. A band saw was then used to section the epiphyses of the humeral condyle, talus, and calcaneus into 3-4 $\mathrm{mm}$ parallel slabs in a sagittal plane. A score for OC was assigned based on the macroscopic appearance of the cut surfaces of the slabs. The criteria for scoring OC lesions are provided in Table 1 and represent a modification of earlier proposed scoring systems
$[20,30]$ for expressing the severity of a given pathological process.

The right and left joint were scored independently. If more than one osteochondral lesion occurred in the same location, the highest score was used for analysis.

All osteochondral lesions were photographed with a digital camera (Canon Rebel XTi Model DS126151, DC $8.1 \mathrm{~V})$, and the scored slabs from each joint were immersed in $10 \%$ neutral buffered formalin. In slabs where the score was unclear macroscopically, the score was decided microscopically. These slabs, and slabs from joints with lesions that were regarded as typical for osteochondrosis, were decalcified in $3.4 \%(\mathrm{w} / \mathrm{v})$ sodium formate and $15.5 \%(\mathrm{v} / \mathrm{v})$ formic acid, prepared on histological slides $(5 \mu \mathrm{m})$, and stained with haematoxylin and eosin for microscopic evaluation.

\section{Statistical analysis}

The data were analysed using SAS v. 9.3 (SAS Institute. Inc., Cary, NC). The highest score of each variable in the left and right joint of each animal was used for statistical analysis. In addition to calculating frequencies and odds ratios on raw data, Spearman rank correlations between the $\mathrm{OC}$ scores of the corresponding right and left joints were calculated from their residual values after applying a linear model including the fixed effects of group, sex, and the regression of carcass weight. We estimated the effects of housing and sex on binary response variables using the GENMOD Procedure (logit link function in SAS). The analysed binary variables were the presence of OC (score $0 /$ score $1-5$ ), the severity of OC (two categories, $0-2$ or 3-5), and the presence of OCD (score $0-4 /$ score 5) in specific locations. The statistical model included the effects of group, sex, and the regression of carcass weight. The interaction between group and sex was included and tested in the initial model but was not significant for any of the analysed traits so was eliminated from the final model. Least-square means (adjusted means of proportions) were estimated using the inverse link

Table 1 Grading scale for osteochondrosis lesions in the articular cartilage complex and subchondral bone tissue

\begin{tabular}{|c|c|c|c|c|c|}
\hline & Score 1 & Score 2 & Score 3 & Score 4 & Score 5 \\
\hline \multicolumn{6}{|l|}{ Articular cartilage complex } \\
\hline Thickened cartilage (focal necrotic cartilage)* & + & + & ++ & ++ & ++ \\
\hline Separation in osteochondral junction & - & - & + & ++ & ++ \\
\hline Cleft(s) in articular cartilage & - & - & $+/-$ & $+/-$ & ++ \\
\hline \multicolumn{6}{|l|}{ Subchondral bone tissue } \\
\hline Hyperaemia, haemorrhage & - & + & + & ++ & ++ \\
\hline Necrosis/fibrosis, subchondral cysts & - & $+/-$ & + & ++ & ++ \\
\hline Extent of lesion & Minor & Small & Moderate & Extensive & Severe \\
\hline
\end{tabular}

Lesions were assessed as minor-small (+), moderate-extensive (++), varying presence (+/-), or not present (-). A score of 0 reflected normal tissue with no osteochondral lesions; scores 1-5 indicated increasing size and number of lesions. *Lesions that were difficult to diagnose macroscopically were examined histologically for areas of necrotic cartilage. 
option. In addition, the presence of synovitis, kissing lesions (i.e. abrasions in the articular cartilage and sometimes in the underlying subchondral bone, seen opposite an $\mathrm{OC}$ lesion), and any pathological lesion (including $\mathrm{OC}$ ) in any location of every joint were examined statistically. Significance was defined as $p \leq 0.05$.

\section{Results}

Fourteen pigs were excluded from the study; three freerange and four confined pigs lost both ear tags; three free-range pigs were euthanised because of illness (one each with low growth rate, chronic pneumonia, and purulent arthritis and osteomyelitis in an elbow joint) before reaching 20 weeks of age; three free-range pigs did not reach slaughter weight until after seven months of age; and one confined pig was excluded due to missing slaughter data. The remaining 136 pigs (91 freerange, 45 confined) were included in the analyses as they showed good health and needed no treatment for disease during the growth period.

We examined 272 elbow and hock joints (136 right and left). Due to the difference in numbers of free-range (91) and confined (45) pigs, the results are presented as percentages of lesions. Inspection of the distal medial and lateral talus and the mediodistal calcaneus was not performed for the first 32 pigs because of an oversight, so the results for these locations were obtained from 104 pigs.

\section{Osteochondral lesions}

The OC data are based on the scores from the slab examination. In total, 130 pigs had OC in at least one location in one or more joints. Typical OC lesions viewed macro- and microscopically on slabs are illustrated in Figure 1. OC lesions with score 4 or 5 showed depressions or irregularities at the surface of the articular cartilage, but the presence of these depressions varied in OC lesions with score 1,2 , or 3 .

The presence and severity of osteochondral lesions in the joints of free-range and confined pigs are presented in Table 2 (elbows) and Table 3 (hocks).

\section{Osteochondrosis in the elbow joints}

The percentage of pigs with an OC score in any location of the elbow joint was $68.1 \%$ in the free-range group and $53.3 \%$ in the confined group (odds ratio 1.9, i.e. the odds of $\mathrm{OC}$ in the elbow was 1.9 times greater in the free-range than confined pigs). Pigs from both groups had greater number of and more severe lesions in the medial aspect of the humeral condyle than in the lateral aspect. The percentage of pigs that had an OC score of 3, 4, or 5 in any location of the elbow joint was $33 \%$ in the free-range group and $15.6 \%$ in the confined group (odds ratio 2.7).
Kissing lesions were apparent on joint surfaces opposite some of the larger OCD lesions in the medial humeral condyle in $4 \%$ of the right and $6 \%$ of the left elbow joints of free-range pigs, but were not found in any of the confined pigs. The kissing lesions affected areas of the semilunar notch, anconeus, and/or the proximal anterior ridge of the radius.

\section{Osteochondrosis in the hock joints}

OC lesions in the hock joint occurred in $82.4 \%$ of freerange and $64.4 \%$ of confined pigs with an odds ratio of 2.6. In both groups, OC was most prevalent in the distal medial and lateral parts of the talus. The severity of osteochondral lesions, calculated as the percentage of animals with an OC score of 3,4 or 5 in any location, was $69.2 \%$ in the free-range group and $35.5 \%$ in the confined group (odds ratio 4.1).

The most common and severe lesions occurred on the medial side of the articular surface in both groups. However, in the free-range group, OC was also common in the coracoid process of the calcaneus. Of the 36 freerange pigs that had an OCD lesion in one or both hock joints, the lesion occurred in only the coracoid process in 17 animals and in both the coracoid process and the medial proximal trochlea in 10 animals. Only four pigs in the confined group had OCD, two in the coracoid process and two in the medial proximal trochlea. The osteochondral lesions in the lateral distal talus and mediodistal calcaneus were all mild to moderate (OC score of 1,2 , or 3 ) in all pigs.

Lesions of the coracoid process were $2-15 \mathrm{~mm}$ in diameter with fragments of necrotic articular cartilage and single or multiple cleft formations, sometimes exposing underlying subchondral bone (Figure $2 \mathrm{~A}$ and $\mathrm{B}$ ). In a few of the cases with scores of $5 / O C D$ we found clefts in the articular epiphyseal cartilage complex (AECC) and the cartilage had a yellowish discolouration. Histologically the AECC lacked obvious cartilage thickening and only a minor necrosis of cartilage and minor reaction in the subchondral bone was observed. Rare cases had large osteochondral fragments that were up to $0.8 \mathrm{~mm}$ in diameter and were associated with clefts of the articular cartilage (Figure 2C).

Kissing lesions were primarily observed on the articular surfaces of the lateral malleolus of the fibula and the distal tibia. Kissing lesions were common in free-range pigs and were found in $20.8 \%$ and $13.2 \%$ of pigs on the right and left articular surface of the distal tibia, respectively, and in $27.5 \%$ and $19.8 \%$ of pigs on the right and the left lateral malleolus of the fibula, respectively. Only $4.4 \%$ of confined pigs had kissing lesions on the right distal tibia, and $2.2 \%$ of confined pigs had them on the right lateral malleolus of the fibula. 


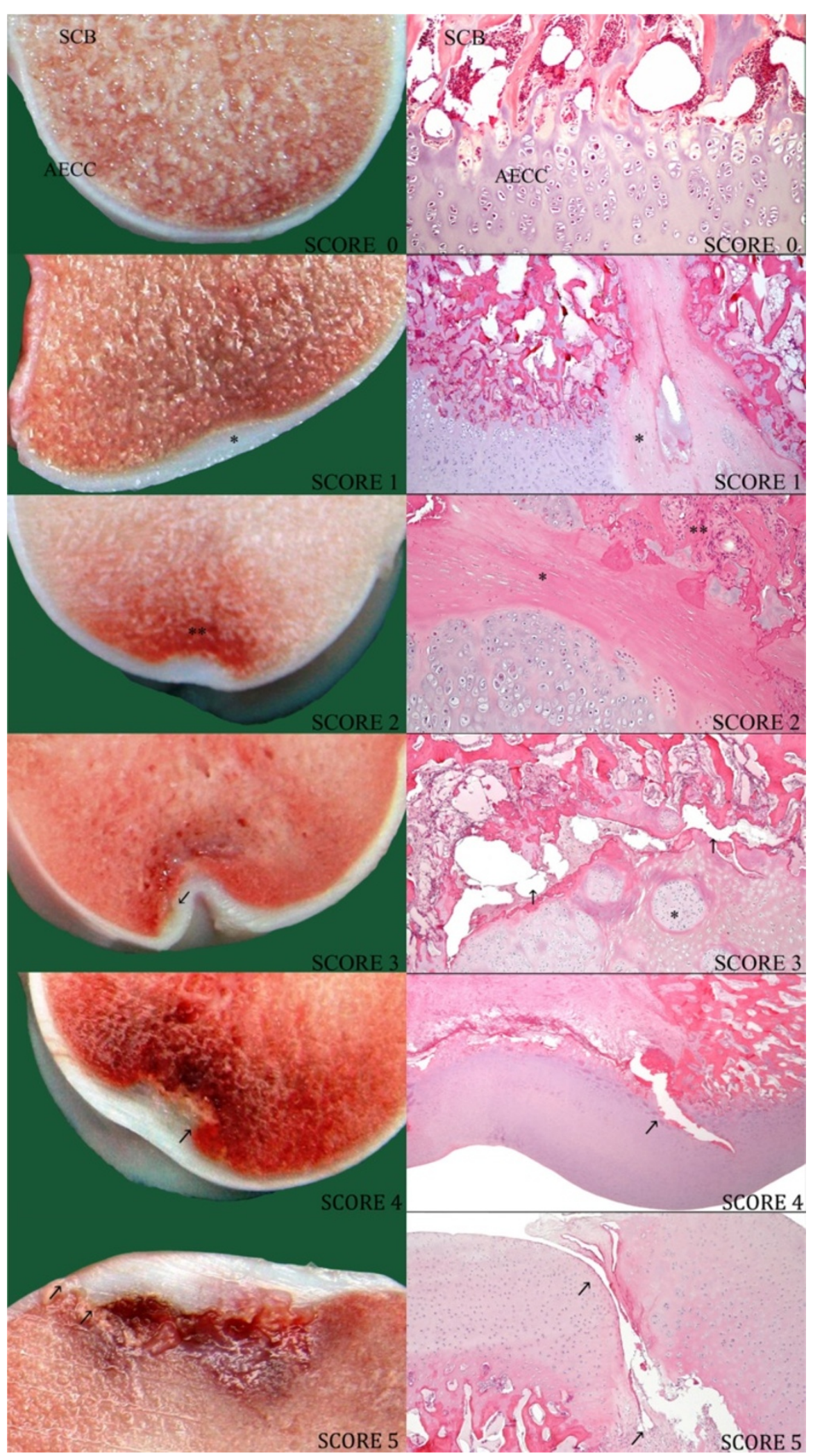

Figure 1 (See legend on next page.) 
(See figure on previous page.)

Figure 1 Osteochondral lesions in the articular epiphyseal cartilage complex and subchondral bone of the talus. These six macro- and microscopic images of slabs from the tali of different pigs show lesions that are characteristic of each osteochondrosis (OC) score. Together, they illustrate how lesions develops from minor OC (scores 1 and 2) through moderate to extensive OC (scores 3 and 4 ) and finally to OC dissecans (score 5). Open spaces in the microscopic images are artefacts. Score 0: No lesions in the articular epiphyseal cartilage complex (AECC) and subchondral bone $(\mathrm{SCB})$ (medial distal talus, figure size $\times 10$ ). Score 1: Minimal focal thickening* of the AECC with necrotic cartilage visible histologically (lateral distal talus, $\times 4$ ). Score 2: Small focal thickening and necrosis in the AECC with vascular and/or inflammatory** reaction in subchondral bone (medial distal talus, $\times 10$ ). Score 3 : Moderate lesions in the AECC and underlying bone with minor separation (arrows) in the osteochondral junction. Focal chondrocyte clusters* are seen (medial distal talus, $\times 4$ ). Score 4: Extensive lesions in the AECC and underlying bone where separation (arrows) is visible in both cartilage and subchondral bone (medial distal talus, $\times 1$ ). Score 5: Osteochondrosis dissecans. Severe lesion with clefts that cut through the surface of the cartilage (arrows) with necrosis in the AECC and involvement of subchondral bone (medial trochlea of the talus, $\times 1$ ).

When OCD was present only in the coracoid process, the kissing lesions occurred on the lateral malleolus of the fibula. When OCD occurred in the medial or lateral proximal trochlea of the talus, there were always lesions on the articular surfaces of the lateral malleolus of the fibula and the distal tibia as well.

\section{Assessing osteochondrosis on articular surface compared to slab examination}

The percentage of $\mathrm{OC}$ recognized by inspection of intact joint surfaces was compared to the results recorded by examination of slabs to determine how many of the OC lesions were missed or misdiagnosed by relying on surface examination alone. All OC lesions with scores of 4 or 5 were apparent by surface examination but the majority of OC lesions with score 1, 2, or 3 were only diagnosed by slab examination. Only $37 \%$ of the OC lesions in the medial part and $15 \%$ of the OC lesions in the lateral part of the humeral condyle diagnosed on slab examination were recognized by surface inspection. In the hock, none of the OC lesions revealed by slab examination of the mediodistal calcaneus were recognized on the intact joint surface. In the other anatomical locations (the trochlea and distal aspect of the medial and lateral talus and the coracoid process of calcaneus) of the hock joint, surface inspection recognized $74 \%, 76 \%, 62 \%, 38 \%$ and $93 \%$ respectively, of the OC lesions seen on slab examination.
Small irregularities and depressions occasionally seen in the articular surfaces were occasionally mistaken for OC lesions on surface inspection, but in these cases the slabs and histology of these lesions showed no visible underlying pathological lesions.

\section{Synovitis}

Non-purulent chronic synovitis was found mainly in the presence of OCD (in $9.4 \%$ of the elbow joints and $30.7 \%$ of the hock joints in the free-range pigs, and in $3.3 \%$ of elbow joints and $3.3 \%$ of hock joints in the confined group). This condition was also seen in a few free-range pigs that did not have OCD (in $0.82 \%$ of the elbow and hock joints), but was not seen in any OCD-free confined pigs.

\section{Synovitis and $O C D$}

Synovitis that was histologically characterised by synovial cell hyperplasia and hypertrophy, and by the infiltration of low numbers of scattered lymphocytes and plasma cells, occurred in all joints with OCD. However, the degree of inflammation varied according to the size and location of the OCD lesion. All OCD lesions in the medial and lateral part of the humeral condyle or in the trochlea and distal parts of the talus occurred in association with synovitis and presented a moderate to substantial increase in serosanguinous synovial fluid, which sometimes contained small quantities of fibrin. These joints were all visibly swollen. Most OCD lesions in the coracoid process were associated with a local hyperemic

Table 2 Distribution (percentage) of osteochondrosis (OC) scores in the right and left elbow joints

\begin{tabular}{|c|c|c|c|c|c|c|c|c|c|}
\hline Humeral condyle & Group & Joint & OC 0 & OC 1 & OC 2 & OC 3 & OC 4 & OC 5 & Total OC \\
\hline \multirow[t]{4}{*}{ Medial aspect } & Free-range & Right & 60 & 10 & 10 & 4 & 7 & 9 & 40 \\
\hline & & Left & 58 & 9 & 6 & 9 & 9 & 9 & 42 \\
\hline & Confined & Right & 71 & 9 & 9 & 4 & 3 & 4 & 29 \\
\hline & & Left & 71 & 9 & 13 & 5 & 0 & 2 & 29 \\
\hline \multirow[t]{4}{*}{ Lateral aspect } & Free-range & Right & 78 & 16 & 6 & 0 & 0 & 0 & 22 \\
\hline & & Left & 80 & 14 & 3 & 0 & 1 & 2 & 20 \\
\hline & Confined & Right & 73 & 18 & 2 & 7 & 0 & 0 & 27 \\
\hline & & Left & 76 & 18 & 2 & 2 & 2 & 0 & 24 \\
\hline
\end{tabular}

The results are rounded. Number of examined animals: free-range $=91$, confined $=45$. 
Table 3 Distribution (percentage) of osteochondrosis $(O C)$ scores in the right and left hock joints

\begin{tabular}{|c|c|c|c|c|c|c|c|c|c|}
\hline Humeral condyle & Group & Joint & OC 0 & OC 1 & OC 2 & OC 3 & OC 4 & OC 5 & Total OC \\
\hline \multirow[t]{4}{*}{ Medial talus trochlea } & Free-range & Right & 70 & 4 & 6 & 2 & 0 & 18 & 30 \\
\hline & & Left & 71 & 6 & 6 & 4 & 0 & 13 & 29 \\
\hline & Confined & Right & 85 & 9 & 3 & 0 & 0 & 3 & 15 \\
\hline & & Left & 78 & 11 & 4 & 7 & 0 & 0 & 22 \\
\hline \multirow[t]{4}{*}{ Medial talus distal* } & Free-range & Right & 47 & 3 & 16 & 28 & 4 & 2 & 53 \\
\hline & & Left & 43 & 6 & 19 & 28 & 4 & 0 & 57 \\
\hline & Confined & Right & 61 & 3 & 19 & 17 & 0 & 0 & 39 \\
\hline & & Left & 61 & 8 & 17 & 11 & 3 & 0 & 39 \\
\hline \multirow[t]{4}{*}{ Lateral talus trochlea } & Free-range & Right & 81 & 8 & 6 & 3 & 1 & 1 & 19 \\
\hline & & Left & 82 & 6 & 3 & 8 & 0 & 1 & 18 \\
\hline & Confined & Right & 91 & 9 & 0 & 0 & 0 & 0 & 9 \\
\hline & & Left & 82 & 9 & 9 & 0 & 0 & 0 & 18 \\
\hline \multirow[t]{4}{*}{ Lateral talus distal* } & Free-range & Right & 60 & 13 & 19 & 8 & 0 & 0 & 40 \\
\hline & & Left & 62 & 13 & 15 & 10 & 0 & 0 & 38 \\
\hline & Confined & Right & 64 & 17 & 17 & 2 & 0 & 0 & 36 \\
\hline & & Left & 64 & 8 & 22 & 6 & 0 & 0 & 36 \\
\hline \multirow[t]{4}{*}{ Calcaneus coracoid process } & Free-range & Right & 74 & 1 & 1 & 0 & 0 & 24 & 26 \\
\hline & & Left & 72 & 0 & 3 & 1 & 1 & 23 & 28 \\
\hline & Confined & Right & 93 & 0 & 2 & 0 & 0 & 5 & 7 \\
\hline & & Left & 98 & 0 & 0 & 0 & 2 & 0 & 2 \\
\hline \multirow[t]{4}{*}{ Calcaneus mediodistal* } & Free-range & Right & 75 & 7 & 16 & 2 & 0 & 0 & 25 \\
\hline & & Left & 75 & 6 & 15 & 4 & 0 & 0 & 25 \\
\hline & Confined & Right & 88 & 6 & 6 & 0 & 0 & 0 & 12 \\
\hline & & Left & 80 & 6 & 14 & 0 & 0 & 0 & 20 \\
\hline
\end{tabular}

The values are rounded. Number of examined animals: free-range $=91$, confined $=45$.

*These joint sites were examined in 68 free-range and 36 confined pigs.

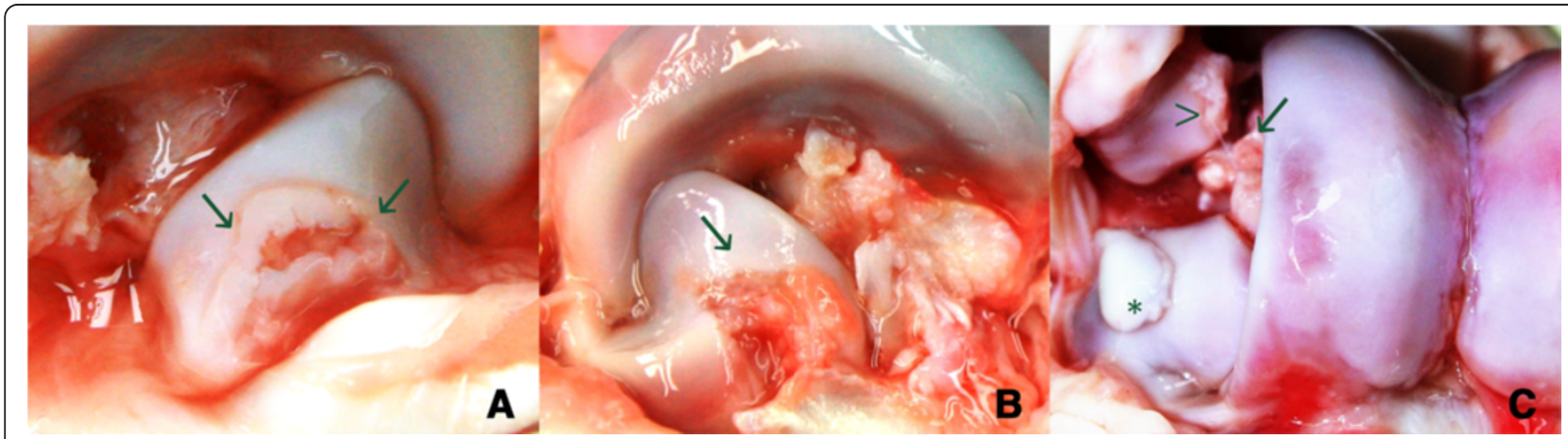

Figure 2 Osteochondrosis dissecans lesions in the coracoid process of calcaneus. A. Lateral close-up of the right coracoid process: multiple clefts in the articular cartilage expose underlying subchondral bone tissue and have caused synovitis with increased amounts of transparent/ slightly haemorrhagic synovial fluid. B. Lateral view of the left coracoid process: a large fragment of articular cartilage has loosened from the subchondral bone tissue (arrow). The exposed bone and surrounding synovial and soft tissues are inflamed. C. Frontal view of the right lateral trochlea and coracoid process: osteochondral fragment $\left(^{*}\right)$ adherent on the surface of the coracoid process. Kissing lesions on the lateral malleolus of the fibula (arrowhead) and fascies articularis malleolaris of the talus (arrow) are also seen. 
reaction of the synovial. Only $21 \%$ of joints with a solitary OCD lesion in this location had marked synovitis and visible swelling.

\section{Non-purulent synovitis without $O C D$}

One free-range pig had bilateral non-purulent synovitis with no OC lesions in the right elbow joint and an OC score of 1 in the lateral aspect of the condyle of the left elbow joint. In both locations, the synovitis was characterised by hypertrophic and hyperemic villi with marked neovascularisation and infiltration of lymphocytes, plasma cells, and macrophages in the subsynovial connective tissue. In another case, a right hock joint with an OC score of 2 also had chronic proliferative synovitis with marked mature granulation tissue. Gram staining did not reveal bacteria in any of these cases.

\section{Other lesions}

Other lesions were recorded only in elbow joints and were seen equivalently in free-range and confined pigs. These lesions included two joints with large haemorrhages in the capsule and synovial membrane. Four joints with partial ruptures and haemorrhages and three joints with minor haemorrhages were also observed in the collateral ligaments at their origin on the humerus. Seven joints had minor- to medium-sized fractures in the anconeus growth plate, with mild to moderate inflammation in the subchondral bone and synovial membrane.

Effects of housing, sex, and weight on the prevalence and severity of osteochondrosis

Statistical results estimated by least squares analysis (GENMOD) for groups and sex are presented in Table 4 (elbow) and Table 5 (hock).

\section{Free-range versus confined housing}

Free-range pigs had more severe $\mathrm{OC}$ in the medial aspect of the humeral condyle than confined pigs $(p<0.05)$, and the prevalence of $\mathrm{OC}$ in all locations of the elbow joints was significantly higher $(p<0.05)$ in the free-range pigs. In addition, free-range pigs had a higher prevalence of $\mathrm{OC}$ in the medial distal talus $(p<0.01)$ and the coracoid process $(p<0.001)$, and more severe $\mathrm{OC}$ in the lateral trochlea $(p<0.01)$, the medial distal talus $(p<0.05)$ and the coracoid process $(p<0.001)$ of the hock joints compared to the confined pigs. In the hocks, OCD was more prevalent in the medial trochlea $(p<0.05)$ and the coracoid process $(p<0.001)$ of free-range pigs, as were synovitis $(p<0.001)$ and kissing lesions in the distal tibia $(p<0.05)$ and lateral malleolus of the fibula $(p<0.001)$. Osteochondrosis in the medial trochlea of the talus and the coracoid process contributed the most to the higher overall prevalence $(p<0.05)$ and severity $(p<0.001)$ of OC in the hock joints of the free-range pigs.

\section{Sex}

The free-range group included 37 castrated pigs and 54 gilts, the confined group included 22 castrated pigs and 23 gilts. The prevalence of $\mathrm{OC}$ in the lateral aspect of the humeral condyle of the elbow joints was higher $(p<$ $0.05)$ in the gilts than in the castrates, while castrates had a higher prevalence of $\mathrm{OC}$ in the medial and the lateral distal talus $(p<0.05)$. The sexes showed no significant differences in $\mathrm{OC}$ in the other locations.

\section{Weight}

The mean $( \pm \mathrm{SD})$ slaughter weight of free-range and confined pigs was $91.7 \pm 5.3$ and $96.0 \pm 7.2 \mathrm{~kg}$, respectively, and free-range pigs were slaughtered $6 \pm 3$ days later than confined pigs. Slaughter weight did not have a

Table 4 Estimated least squares means by group and sex for elbow joint lesions

\begin{tabular}{|c|c|c|c|c|c|c|c|}
\hline \multirow[t]{2}{*}{ Location } & \multirow[t]{2}{*}{ Lesion } & \multicolumn{3}{|l|}{ Group } & \multicolumn{3}{|l|}{ Sex } \\
\hline & & Free-range & Confined & Sign. & Gilt & Castrate & Sign. \\
\hline \multirow[t]{3}{*}{ Humeral condyle medial aspect } & OC $1-5$ & 0.55 & 0.36 & n.s. & 0.37 & 0.54 & n.s. \\
\hline & OC $3-5$ & 0.32 & 0.12 & $* *$ & 0.16 & 0.24 & n.s. \\
\hline & OCD & 0.11 & 0.05 & n.s. & 0.05 & 0.11 & n.s. \\
\hline \multirow[t]{3}{*}{ Humeral condyle lateral aspect } & OC $1-5$ & 0.31 & 0.28 & n.s. & 0.41 & 0.21 & * \\
\hline & OC $3-5$ & 0.02 & 0.04 & n.s. & 0.07 & 0.02 & n.s. \\
\hline & OCD & 0.00 & 0.00 & n.s. & 0.00 & 0.00 & n.s. \\
\hline \multirow[t]{2}{*}{ All locations } & OC $1-5$ & 0.69 & 0.50 & * & 0.63 & 0.58 & n.s. \\
\hline & OC 3-5 & 0.33 & 0.16 & * & 0.21 & 0.25 & n.s. \\
\hline Synovium & Synovitis & 0.15 & 0.04 & n.s. & 0.06 & 0.10 & n.s. \\
\hline All locations & Any lesion & 0.68 & 0.52 & n.s. & 0.65 & 0.56 & n.s. \\
\hline
\end{tabular}

Measures of prevalence (score 1-5) and severity (score 3-5) of osteochondrosis (OC) and prevalence of osteochondrosis dissecans (OCD), synovitis, and any lesion

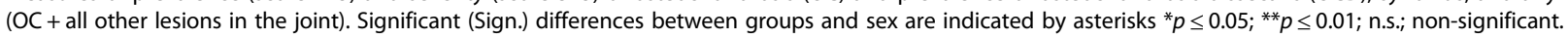


Table 5 Estimated least squares means by group and sex for hock joint lesions

\begin{tabular}{|c|c|c|c|c|c|c|c|}
\hline \multirow[t]{2}{*}{ Location } & \multirow[t]{2}{*}{ Lesion } & \multicolumn{3}{|l|}{ Group } & \multicolumn{3}{|l|}{$\underline{\text { Sex }}$} \\
\hline & & Free-range & Confined & Sign. & Gilt & Castrate & Sign. \\
\hline \multirow[t]{3}{*}{ Medial talus trochlea } & OC $1-5$ & 0.41 & 0.24 & n.s. & 0.29 & 0.35 & n.s. \\
\hline & OC $3-5$ & 0.26 & 0.12 & n.s. & 0.15 & 0.21 & n.s. \\
\hline & OCD & 0.17 & 0.05 & * & 0.10 & 0.08 & n.s. \\
\hline \multirow[t]{3}{*}{ Medial talus distal } & OC $1-5$ & 0.78 & 0.47 & $* *$ & 0.52 & 0.74 & * \\
\hline & OC $3-5$ & 0.49 & 0.25 & * & 0.34 & 0.38 & n.s. \\
\hline & OCD & 0.00 & 0.00 & n.s. & 0.00 & 0.00 & n.s. \\
\hline \multirow[t]{3}{*}{ Lateral talus trochlea } & OC $1-5$ & 0.28 & 0.21 & n.s. & 0.31 & 0.19 & n.s. \\
\hline & OC $3-5$ & 0.13 & 0.00 & $* * *$ & 0.00 & 0.00 & n.s. \\
\hline & OCD & 0.00 & 0.00 & n.s. & 0.00 & 0.00 & n.s. \\
\hline Lateral talus distal $^{\wedge}$ & OC $1-5$ & 0.58 & 0.42 & n.s. & 0.37 & 0.63 & * \\
\hline \multirow[t]{3}{*}{ Coracoid process } & OC $1-5$ & 0.35 & 0.09 & $* * *$ & 0.22 & 0.16 & n.s. \\
\hline & OC $3-5$ & 0.32 & 0.07 & $* * *$ & 0.19 & 0.13 & n.s. \\
\hline & OCD & 0.31 & 0.04 & $* * *$ & 0.15 & 0.10 & n.s. \\
\hline Calcaneus mediodistal $^{\wedge}$ & OC $1-5$ & 0.37 & 0.21 & n.s. & 0.25 & 0.32 & n.s. \\
\hline \multirow[t]{2}{*}{ All locations } & OC $1-5$ & 0.83 & 0.62 & * & 0.72 & 0.76 & n.s. \\
\hline & OC $3-5$ & 0.69 & 0.33 & $* * *$ & 0.47 & 0.57 & n.s. \\
\hline Tibia, distal & Kissing lesion & 0.18 & 0.05 & * & 0.11 & 0.08 & n.s. \\
\hline Lateral malleolus & Kissing lesion & 0.28 & 0.02 & $* * *$ & 0.09 & 0.09 & n.s. \\
\hline Synovium & Synovitis & 0.39 & 0.07 & $* * *$ & 0.21 & 0.16 & n.s. \\
\hline All locations & Any lesion & 0.83 & 0.65 & n.s. & 0.76 & 0.74 & n.s. \\
\hline
\end{tabular}

Measures of prevalence (score 1-5) and severity (score 3-5) of osteochondrosis (OC) and prevalence of osteochondrosis dissecans (OCD), synovitis, and any lesion (OC and all other lesions in the joint). Significant (Sign.) differences between groups and sex are indicated by asterisks ${ }^{*} p \leq 0.05$; ${ }^{* *} p \leq 0.01 ;{ }^{* * *} p \leq 0.001 ;$ n.s.; non-significant. ^Only the difference in prevalence of OC was examined, as no cases of OC score 4-5 were recorded.

significant effect on the prevalence or severity of OC in any location of either joint.

\section{Correlations between OC scores in specific locations}

No significant differences in the prevalence of $\mathrm{OC}$ were found between the left and right sides of either joint. Weak to moderate $(r=0.32-0.61)$ but significant $(p<0.01)$ associations between the left and right OC scores were noted for most locations (Table 6, elbow; Table 7, hock). Weak to moderate $(r=0.24-0.48, p<0.01)$ correlation were also registered between the left and the right $\mathrm{OC}$ scores of the coracoid process of the calcaneus and the medial, respectively the lateral trochlea of talus.

\section{Joints condemned at slaughter}

The pathoanatomical examination showed that a total of 41 joints (elbow and hock joints included) had OCD with obvious synovitis (large amounts of synovial fluid and proliferated synovial membrane). The abattoir condemned five joints (one left and one right elbow joint and two right and one left hock joint) from four freerange pigs at slaughter, representing $1.4 \%$ of all joints (5 out of 364) and $4.4 \%$ of all pigs (4 out of 91) in the freerange group. No joints from confined pigs were condemned at slaughter. All the joints were condemned unopened and classified as arthritis/osteoarthritis by the meat inspectors. All the joints displayed OCD (score 5) and synovitis. Three of the condemned joints occurred in pigs that also had OCD in the opposite joints.

\section{Discussion}

We found a significantly higher prevalence and severity of $\mathrm{OC}$ lesions in the elbow and hock joints of fattening pigs that were allowed to range freely, compared to pigs

Table 6 Spearman rank correlations $(r)$ between osteochondrosis (OC) score in right and left elbow joint

\begin{tabular}{|c|c|c|c|}
\hline & \multirow[b]{2}{*}{ Location } & \multicolumn{2}{|c|}{ OC score left humeral condyle } \\
\hline & & Medial aspect & Lateral aspect \\
\hline \multirow[t]{2}{*}{ OC score right humeral condyle } & Medial aspect & $0.52^{* * *}$ & -0.04 \\
\hline & Lateral aspect & -0.10 & $0.52^{* * *}$ \\
\hline
\end{tabular}

Significance levels: ${ }^{* * *} p \leq 0.001$. 
Table 7 Spearman rank correlations ( $r$ ) between osteochondrosis (OC) score in right and left hock joint

\begin{tabular}{|c|c|c|c|c|c|c|c|c|}
\hline & \multirow{3}{*}{ Location } & & \multicolumn{6}{|c|}{ OC score left hock } \\
\hline & & & \multicolumn{2}{|c|}{ Medial talus } & \multicolumn{2}{|c|}{ Lateral talus } & \multicolumn{2}{|l|}{ Calcaneus } \\
\hline & & & Trochlea & Distal & Trochlea & Distal & Coracoid process & Mediodistal \\
\hline \multirow[t]{6}{*}{ OC score right hock } & Medial Talus & Trochlea & $0.45^{* * *}$ & -0.04 & $0.34^{* * *}$ & -0.07 & $0.36^{* * *}$ & -0.02 \\
\hline & & Distal & -0.05 & $0.32^{* * *}$ & 0.09 & $0.30^{* *}$ & -0.11 & 0.03 \\
\hline & Lateral Talus & Trochlea & $0.26^{* *}$ & -0.04 & 0.15 & -0.03 & $0.24^{* *}$ & -0.02 \\
\hline & & Distal & 0.09 & 0.06 & 0.00 & $0.46^{* * *}$ & -0.04 & $0.20^{*}$ \\
\hline & Calcaneus & Coracoid process & $0.24 * *$ & -0.01 & $0.48^{* * *}$ & 0.09 & $0.61^{* * *}$ & 0.01 \\
\hline & & Mediodistal & -0.12 & 0.18 & -0.03 & 0.11 & -0.01 & $0.49^{* * *}$ \\
\hline
\end{tabular}

Significance levels: ${ }^{*} p \leq 0.05,{ }^{* *} p \leq 0.01$, and ${ }^{* * *} p \leq 0.001$.

kept in confined housing, and these differences were most pronounced in the hock joints. These findings indicate that this disease may represent a larger health and animal welfare problem in free-range pig production than was previously assumed.

A higher prevalence of chronic joint lesions [31] and lameness [32-34] has been reported in fattening pigs housed in free-range or 'animal-friendly' systems with outdoor runs or pasture than in fattening pigs housed in confined indoor systems. However, Cagienard et al. [35] found no differences in clinical lameness or prevalence of swollen joints in animals in 'animal friendly'/free range and traditional/confined housing systems. Others $[31,36]$ have suggested that the incidence of leg disorders in freerange pigs may be underestimated because of the difficulties in diagnosing individual pigs that are group-housed in large systems. Lameness can be caused by various lesions; none of the above-mentioned studies included post-mortem disarticulation and examination of the joints. However, OC is often associated with leg weakness/ lameness in pigs [15,16,22,37-41] and horses [42-44], and it is likely that $\mathrm{OC}$ lesions contributed to the lameness and swollen joints reported in previous studies.

\section{Housing factors}

All pigs were crossbred Hampshires born and reared in the same herd prior to allocation into two different housing regimes at the age of 12 weeks. During the fattening period, the pigs received identical feed, according to the same feeding protocol and were handled by the same personnel. These facts strongly suggest that the housing environment from the age of 12 weeks to slaughter was an important explanation for the difference in prevalence and severity of OC between the freerange and confined pigs.

Grevenhof et al. [45] reported a lower prevalence of OC in the elbow and tarsocrural joints but a higher prevalence of OCD ('score E') in fattening pigs that were housed indoors on deep straw bedding with a larger space allowance than in pigs housed in confined stalls. Other studies failed to find significant associations between the prevalence of
OC lesions and the type of flooring [46-48], and high stocking density was reported to have a significant effect on the prevalence of $\mathrm{OC}$ in only one location in the elbow [46]. However, the evaluation of osteochondral lesions in these studies was limited to gross inspection of intact joint surfaces. Here, we found that examination of thin, crosssectioned joint slabs revealed a much higher prevalence of $\mathrm{OC}$ than did inspection of intact joint surfaces. Therefore, the prevalence of $\mathrm{OC}$ is likely to be underestimated in studies that use superficial scoring of joint surfaces, and differences among treatments in such studies might not be captured.

A comparative study between outdoor and conventionally housed indoor fattening pigs found that outdoor pigs walked more and were more active overall [49]. We did not measure activity in this study, but a main difference between the two housing systems was likely to have been the amount and type of activity among the pigs. Pigs in confined pens spend up to $80 \%$ of their time lying down [16], whereas pigs in an enriched environment are more active [50-53] and spend more time on exploratory activities, running, and jumping. Greater activity levels inherently result in a greater magnitude and diversity of biomechanical forces exerted on the joint structures. There are similarities between the forms of osteochondrosis that occur in humans and animals [54]; in humans, increased physical activity appears to promote the development of OC/OCD, either through biomechanical stress or repetitive trauma [55,56]. Activity has also been proposed as a cause of high prevalence of $\mathrm{OC}$ and lameness in joints of pigs in outdoor herds [57]. Other studies have shown that indoor exercise has positive effects on muscles and bones, improves locomotor ability [58], or has no effect on prevalence and severity of OC [58-60]. However, these studies used relatively small samples and in two of them bone slabs were not examined. Therefore, it is difficult to compare those results with the findings presented here.

Rather than the quantity of exercise, the nature of the rearing environment and the types of activity promoted by that environment may be the key factors that determine 
the overall biomechanical load on joint structures. The initial step in the formation of OC lesions in pigs and horses is thought to be microtrauma to the vasculature associated with the epiphyseal growth cartilage [18,19,23,24,61,62]. The risk of microtrauma is likely to be substantially higher in pigs that are allowed free-range movement than in confined animals. In addition, acute injury ('macroscopic trauma') may contribute to the progression from osteochondrosis manifesta to osteochondrosis dissecans $[18,22,25]$.

In the present study, numerous environmental factors differed between the two housing groups, some of which could have increased the prevalence of irregular strain and repeated trauma on the joints of the free-range pigs, resulting in the differences in prevalence and severity of OC. Free-range pigs were housed in large groups with a large roaming area, variable flooring and soil hardness, uneven and stony pasture, and a high threshold between the deep straw bed and the feeding area. This threshold varied between 50 and 125 centimeters depending on the straw level and appeared to be increasingly difficult for the pigs to negotiate as their body mass increased. These housing factors might have had individual or interacting influences on the biomechanical stressors experienced by free-range pigs, and consequently on the development of OC. We do not have sufficient data to distinguish which factors were most important in this study. Additional studies involving more free-range farms are needed to examine the role of activity and the effects of various housing factors on the prevalence of $\mathrm{OC}$ in pigs.

\section{Osteochondrosis in the elbow and hock joints}

Comparison of OC results obtained by inspection of intact surfaces and joint slabs showed that examination of intact articular surfaces would not identify many OC lesions with scores of 1,2 , or 3 . Hence, we will limit our discussion to the results of the slab inspection.

The major difference in $\mathrm{OC}$ in the elbow joints of the two groups was that the free-range pigs had a significantly higher prevalence and more severe lesions in the medial aspect of the humeral condyle. The prevalence of $\mathrm{OC}$ and $\mathrm{OCD}$ in the medial aspect of the humeral condyle were within the ranges (OC, 6\%-83.5\%; OCD 1\%-19\%) reported in other studies of fattening pigs [38,45,63-66]. The prevalence and the severity of OC in both groups were higher in the hock joints than in the elbow joints. Grevenhof and colleagues [45] examined multiple joints and also found the highest prevalence of $\mathrm{OC}$ in the hock joint. High disease incidence (up to 76\%) in the hock have also been reported in other studies [21,22,30].

We did not find previous reports on lesions in the mediodistal calcaneus; these lesions were only observed in slab sections and thus are easy to overlook.
Osteochondral lesions in the coracoid process in fattening pigs have also not been reported previously, which may be explained by low incidence of this type of lesion in confined pigs, evident also in the present study. The coracoid process is of interest because the largest difference in prevalence and severity of OC between free-range and confined pigs was found at this lateral location. Previous reports have suggested that medial rather than lateral locations are prone to OC $[16,18,22]$. Furthermore, score 1-4 lesions were uncommon in the coracoid process and a variation in the extent of lesions present in score 5 lesions in this location indicated that the underlying pathological processes leading to clefts in the AECC might differ. Score 5 lesions that lacked substantial cartilage necrosis and thickening of the AECC might represent foci of $\mathrm{OC}$ that formed early in the life of the pig. After formation, the primary lesion might have resolved or been repaired, leaving only the cleaved joint cartilage as a visible manifestation. Because the majority of the lesions in the coracoid process were located on the most exposed area (the dorsolateral border), it is also possible that blunt acute trauma could have initiated some of the lesions in this location. Depending on its severity, trauma may only affect (i.e. cleave) the superficial articular cartilage or it may impair the blood supply in the cartilage canals of the AECC and so initiate osteochondrosis.

A central question is why an increase in presumably natural behaviour within presumed physiological limits should cause an increase in the prevalence and severity of osteochondrosis. Grøndalen [26] proposed that a certain conformation of the stifle joint causes local overloading in an area of the femoral condyle, which results in OC. Combining this information with current understanding of the pathogenesis of OC [18], we suggest that modern pigs, bred for convenient confined housing, have acquired traits that affect joint conformation and/or joint motion and that lead to unaccustomed physiological stress in certain locations of the joint, even during normal activity and motion.

Osteochondrosis manifesta (score 1-4) may develop into OCD (score 5) under the influence of various factors, one of which is mechanical load [18]. Alternatively, score 1,2 , and 3 OC lesions can resolve if they are engulfed by the ossification front and transformed into bone, or may be repaired by replacement with fibrous tissue that later undergoes membranous ossification. In addition, necrotic cartilage retained in the subchondral bone could also develop into a pseudocyst with micro fractures [67]. We cannot predict how the osteochondrosis manifesta lesions observed here would have progressed had the pigs not been slaughtered. Longitudinal studies including radiology, CT, and MRI have been performed in horses [68] and have provided evidence for the potential healing of OC lesions. 


\section{General health}

Most of the pigs in the present study were healthy and there were no general health differences between the two groups. Infectious arthritis was a rare joint lesion in the studied pigs. The effects of high growth rate and high slaughter weight on the development of OC in pigs is often debated $[16,18,20,22,52,65,69]$, but here, the free-range pigs had lower average slaughter weight and greater incidence of $\mathrm{OC}$ than the confined pigs. We did not calculate growth rates in this study. Lundeheim [15] suggested that pigs with severe OC may not thrive and may have poor appetites, which could contribute to lower weights at slaughter.

\section{Correlations between $\mathrm{OC}$ scores in specific locations}

Osteochondrosis is thought to be bilaterally symmetrical [21,22], and many studies of OC in pigs have included either the left or right leg but not both. Our findings showed that side does not have a systematic influence on the prevalence of OC. However, there was only a weak or moderate correlation between scores of OC lesions in a given location in the left and the right joints, which indicates that examining both legs provides a more complete picture of the severity of $\mathrm{OC}$ in specific joints. A weak to moderate association between the $\mathrm{OC}$ scores of the left and the right coracoid process of calcaneus and the medial, respectively the lateral trochlea of talus, indicates that a factor common to all of these locations influences the development of OC. The distal surfaces of the tarsocrural joint are all affected by variation in movement and load of the right and left distal tibia/ fibula, which could help to explain the association between OC scores in these locations.

These findings, and the fact that significant differences in the prevalence and severity of OC between free-range and confined pigs occurred in only some joint locations, support the assumption that local and temporal factors affect the progression of $\mathrm{OC}$. These factors include biomechanical forces associated with increased magnitude and diversity of activity.

\section{Joint condemnations}

The large number of joints that had OCD lesions with clear synovitis (41), and the very low number of condemned joints (5) clearly showed that inspection of unopened joints at slaughter fails to identify a considerable proportion of joints with pathological lesions. If joint condemnations captured those with synovitis/arthritis and $\mathrm{OC}$ scores of 4 or 5 , condemnation rates could be used in large epidemiological studies as a simple estimate of joint health in fattening pigs. However, our results show that joint condemnations provide a poor estimate of the prevalence of joint lesions in fattening pigs. Therefore, epidemiological studies on joint health that contain conclusions based only on condemnation rates are likely to be of limited value.

\section{Conclusions}

This study indicated that the type of housing environment from the age of 12 weeks to slaughter, allowing either a high or low level of motion and activity, has a substantial effect on the development of OC in pigs. The results support our hypothesis that the increased magnitude and diversity of biomechanical stress experienced by free-range pigs promotes the development of OC. Further research is required to confirm our findings and should focus on the role of activity and the ways in which housing variables (e.g. group size, roaming area, outdoor pasture, flooring, and thresholds) may influence the development of OC. Infectious arthritis was not an important cause of joint lesions in the studied pigs. The condemnation rate did not mirror the joint health in the studied population, and conclusions about joint health that are based on condemnation data are likely to be erroneous. Likewise, studies that use scoring of joint lesions after inspection of intact joint surfaces alone will likely fail to report the true prevalence of the lesions.

Many of the joint lesions observed here may cause pain and eventually lead to lameness [40-43]. Free-range housing systems are an essential part of the high animal welfare standards of organic production, providing an environment that allows the animals to express their innate behaviours. More research on the associations between osteochondrosis, lameness/gait, and environmental factors in free-range fattening pig production is needed.

The same breeds are used in organic and conventional pig production systems in Sweden [70], and these breeds have been developed to cope with conventional environments, not free-range housing systems. Breeding of robust pigs that maintain good joint and leg health in freerange environment should also be promoted.

\section{Competing interests}

The authors declare that they have no competing interests.

\section{Authors' contributions}

PE contributed to the study design and performed clinical farm visits, the analyses, interpreted the data, and wrote the manuscript. BY contributed to the interpretation of the data and writing of the manuscript. NL contributed to the study design and provided assistance with the statistical analysis. EH conceived the original study idea and participated in acquisition of funds, clinical visits to the farm, and communication with the farmers and abattoir, and provided the statistics on joint condemnations collected by the SVDHV. JÖ participated in the study design and performed clinical farm visits. SE designed and supervised the project, acquired the funding, participated in the interpretation of results, and helped write the manuscript. All authors revised and approved the manuscript.

\section{Acknowledgements}

We would like to thank the farmers and the Scan abattoir in Skara for participating in this project, and Rolf Grahm for collecting and coding the legs at the abattoir. We also acknowledge Agneta Boström, Beate Hillman, and Tapio Nikkilä at SLU for their laboratory assistance and Lars Hammarsten 
at SVA for his assistance with disarticulation and sawing of the joints. We thank Dr. Anna Wallenbeck for her kind assistance in acquiring ID tags and providing other helpful advice. This project was supported by funding from the Swedish Research Council FORMAS.

\section{Author details}

${ }^{1}$ Section of Pathology, Department of Biomedical Sciences and Veterinary Public Health, Swedish University of Agricultural Sciences (SLU), 75007 Uppsala, Sweden. ${ }^{2}$ Terrestrial Ecology Department, Norwegian Institute for Nature Research (NINA), Trondheim, Norway. ${ }^{3}$ Department of Animal Breeding and Genetics, Swedish University of Agricultural Sciences (SLU), Uppsala, Sweden. ${ }^{4}$ Swedish Animal Health Service (SvDHV), 46432 Mellerud, Sweden. ${ }^{5}$ National Veterinary Institute (SVA), 75189 Uppsala, Sweden.

Received: 26 February 2014 Accepted: 28 August 2014

Published online: 11 September 2014

\section{References}

1. Slaughter statistics; Joint Condemnations in Swedish Fattening Pigs, Swedish Animal Health Service. [http://www.svdhv.org]

2. Heldmer E, Ekman S: Ekologiska grisar har mer ledanmärkningar, vid slakt, än konventionellt uppfödda grisar, Studier för att klargöra orsakerna till detta och för att ta fram förebyggande åtgärder (Pigs in organic production have more joint condemnations at slaughter, than conventionally raised pigs. Studies to clarify the reasons for this and to develop preventive measures). Swedish Board of Agriculture, Report Project nr 25-1135/07, http://fou.sjv.se/ fou/default.lasso, 2009.

3. Kugelberg C, Johansson G, Sjogren U, Bornstein S, Wallgren P: Infectious diseases and ectoparasites of outdoor slaughter pigs. Swed Vet J (SVT) 2001, 53(4):197-204.

4. Hansson I, Hamilton C, Ekman T, Forslund K: Carcass quality in certified organic production compared with conventional livestock production. J Vet Med B 2000, 47(2):111-120.

5. Beskow $P$, Norqvist M, Lundeheim N, Wallgren P: Outdoor pig production in the Northern part of Sweden. Aspects on health and productivity. Swed Vet J (SVT) 2003, 55(4):11-21.

6. Lindsjö J: Grisar ute! En översikt av rutiner och hälsoläge i svenska besättningar med slaktsvinsuppfödning utomhus. In Specialarbete 34. SLU, Skara: Dept. of Animal Hygiene; 1996:56-68.

7. Svendsen J, Wallgren P, Olsson A-C: Effects of Vaccination against Erysipelothrix rhusiopathiae and Hygiene Studies in Organic Slaughter Pig Production. In Proceedings of the 19th IPVS Congress: 16-19 Jul 2006. Copenhagen: 2006:586

8. Engström F: Rödsjukevaccinering i utomhusproduktion av slaktsvin och dess effekt på förekomsten av ledinflammationer. In Slutarbete För Fagdyrlaegeuddannelsen vedr Svinesygdomme FDS2006. Denmark: (ddd.dk); 2008:1-16.

9. Heldmer E, Lundeheim N, Robertsson J: Gross lesions at slaughter in ecological pigs. Swed Vet J (SVT) 2006, 58(13):13-19.

10. Svendsen J, Andersson M, Botermans J, Olsson A-C: Rödsjuka i ekologisk slaktgrisproduktion-en jämförelse mellan vaccinerade och inte vaccinerade grisar. Del 1. Kliniska studier och produktionsresultat. In Fakta från Lantbrukets byggnadsteknik, Info nr.11. SLU, Alnarp: Inst. för lantbrukets byggnadsteknik. 2008.

11. Wallenbeck A, Eliasson C, Alarik M: Associations between pig leg health and lean meat growth in commercial organic herds. In Proceedings of the NJF Seminar 461; Organic farming systems as a driver for change. Bredsten: 2013:167-168.

12. Grøndalen T: Osteochondrosis and arthrosis in pigs. II. Incidence in breeding animals. Acta Vet Scand 1974, 15(1):26-42.

13. Carlson CS, Hilley HD, Meuten DJ, Hagan JM, Moser RL: Effect of reduced growth rate on the prevalence and severity of osteochondrosis in gilts. Am J Vet Re 1988, 49(3):396-402.

14. Ljunggren $\mathrm{G}$, Reiland S: Osteochondrosis in adolescent animals: an endocrine disorder? Calcif Tissue Res 1970, 4(Suppl):150-151.

15. Lundeheim N: Genetic analysis of osteochondrosis and leg weakness in the swedish pig progeny testing scheme. Acta Agr Scand 1987, 37(2):159-173.

16. Nakano T, Brennan JJ, Aherne FX: Leg weakness and osteochondrosis in swine: a review. Can J Anim Sci 1987, 67(4):883-901.
17. Jørgensen B, Andersen S: Genetic parameters for osteochondrosis in Danish Landrace and Yorkshire boars and correlations with leg weakness and production traits. Anim Sci 2000, 71:427-434.

18. Ytrehus B, Carlson CS, Ekman S: Etiology and pathogenesis of osteochondrosis. Vet Path 2007, 44(4):429-448.

19. Carlson CS, Meuten DJ, Richardson DC: Ischemic necrosis of cartilage in spontaneous and experimental lesions of osteochondrosis. Orthop Res 1991, 9(3):317-329.

20. Ytrehus B, Grindflek E, Teige J, Stubsjøen E, Grøndalen T, Carlson CS, Ekman $S:$ The effect of parentage on the prevalence, severity and location of lesions of osteochondrosis in swine. Med A - Physiol Pathol Clin Med 2004, 51(4):188-195.

21. Grøndalen T: Osteochondrosis and arthrosis in pigs. I. Incidence in animals up to $120 \mathrm{~kg}$ live weigth. Acta Vet Scand 1974, 15(1):1-25.

22. Reiland S: Osteochondrosis in the Pig. PhD thesis. Stockholm: The Royal Veterinary College; 1975.

23. Ytrehus B, Carlson CS, Lundeheim N, Mathisen L, Reinholt FP, Teige J, Ekman S: Vascularisation and osteochondrosis of the epiphyseal growth cartilage of the distal femur in pigs - development with age, growth rate, weight and joint shape. Bone 2004, 34(3):454-465.

24. Ytrehus B, Ekman S, Carlson CS, Teige J, Reinholt FP: Focal changes in blood supply during normal epiphyseal growth are central in the pathogenesis of osteochondrosis in pigs. Bone 2004, 35(6):1294-1306.

25. Nakano T, Aherne FX: Involvement of trauma in the pathogenesis of osteochondritis dissecans in swine. Can J V Res 1988, 52(1):154-155.

26. Grøndalen T: Osteochondrosis and arrthrosis in pigs. VII. Relationship to joint shape and exterior conformation. Acta Vet Scand 1974, 15(Suppl.46):1-32.

27. Council Regulation (EC) No 834/2007 of 28 June 2007 on organic production and labelling of organic products and repealing Regulation (EEC) No 2092/91. 2007, http://eur-lex.europa.eu/LexUriServ/LexUriServ.do? uri=OJ:L:2007:189:0001:0023:EN:PDF.

28. KRAV: Regler för KRAV-certifierad produktion (Standards for KRAV production). 2012, http://www.krav.se/sites/www.krav.se/files/aktuellaregler.pdf.

29. Simonsson A: Fodermedel och näringsrekommendationer för gris. Rapport 266 (Feedstuffs and nutrition recommendations for pig). Uppsala: SLU, The Department of Animal Nutrition and Management; 2006. http://www.slu.se/ sv/fakulteter/vh/institutioner/institutionen-for-husdjurens-utfodring-ochvard/verktyg/fodertabeller/fodertabeller-och-naringsrekommendationer-forgris/fodertabell-gris/.

30. Grøndalen T: Osteochondrosis and arthrosis in pigs. III. A comparison of the incidence in young animals of the Norwegian landrace and Yorkshire breeds. Acta Vet Scand 1974, 15(1):43-52.

31. Olsson AC, Svendsen J, Sundelof JA: Organic pig production. Specialmeddelande - Institutionen for Jordbrukets Biosystem och Teknologi, SLU 1996, 224:74.

32. Badertscher R, Schnider R: Fully-slatted housing and systems with litter and exercise yards for finishing pigs. FAT-Berichte, Switzerland 2002, (585):1-8.

33. Schnider R: Health of fattening pigs kept in different housing systems comparison between systems with fully slatted floors and littered multi-surface systems with exercise yards. Schriftenreihe der Eidgenossischen Forschungsanstalt fur Agrarwirtschaft und Landtechnik 2002, 55:163.

34. Krieter J, Schnider R, Tolle $\mathrm{KH}$ : Health conditions of growing-finishing pigs in fully-slatted pens and multi-surface systems. Deut Tierärztl Woch 2004, 111(12):462-466.

35. Cagienard A, Regula G, Danuser J: The impact of different housing systems on health and welfare of grower and finisher pigs in Switzerland. Prev Vet Med 2005, 68(1):49-61.

36. Bonde M, Sørensen JT: Herd health management in organic pig production using a quality assurance system based on Hazard Analysis and Critical Control Points. NJAS - Wagen Life Sci 2004, 52(2):133-143.

37. Stern S, Lundeheim N, Johansson K, Andersson K: Osteochondrosis and leg weakness in pigs selected for lean tissue-growth rate. Livest Prod Sci 1995, 44(1):45-52.

38. Jørgensen B, Arnbjerg J, Aaslyng M: Pathological and radiological investigations on osteochondrosis in pigs, associated with leg weakness. Vet Med A - Zentralb/ Veterinarmed A - Physiol Pathol Clin Med 1995, 42(8):489-504

39. Koning DBD, Grevenhof EMV, Laurenssen BFA, Ducro BJ, Heuven HCM, Groot PND, Hazeleger W, Kemp B: Associations between osteochondrosis 
and conformation and locomotive characteristics in pigs. J Anim Sci 2012, 90(13):4752-4763.

40. Jensen $T B$, Kristensen $H H$, Toft $N$ : Quantifying the impact of lameness on welfare and profitability of finisher pigs using expert opinions. Live Sci 2012, 149(3):209-214.

41. Dewey CE, Friendship RM, Wilson MR: Clinical and postmortem examination of sows culled for lameness. Can Vet J 1993, 34(9):555.

42. Brink P, Dolvik NI, Tverdal A: Lameness and effusion of the tarsocrural joints after arthroscopy of osteochondritis dissecans in horses. Vet Rec 2009, 165(24):709-712

43. Jeffcott LB, Kold SE: Stifle lameness in the horse-a survey of 86 referred cases. Equine Vet J 1982, 14(1):31-39.

44. Schneider RK, Jenson P, Moore RM: Evaluation of cartilage lesions on the medial femoral condyle as a cause of lameness in horses: 11 cases (1988-1994). J Am Vet Med 1997, 210(11):1649-1652.

45. Van Grevenhof EM, Ott S, Hazeleger W, Van Weeren PR, Bijma P, Kemp B: The effects of housing system and feeding level on the joint-specific prevalence of osteochondrosis in fattening pigs. Livest Sci 2011, 135(1):53-61.

46. Jørgensen B: Influence of floor type and stocking density on leg weakness, osteochondrosis and claw disorders in slaughter pigs. Anim Sci 2003, 77:439-449.

47. Perrin WR, Aherne FX, Bowland JP, Hardin RT: Effects of age, breed and floor type on incidence of articular cartilage lesions in pigs. Can J Anim Sci 1978, 58(2):129-138.

48. Scott K, Chennells DJ, Campbell FM, Hunt B, Armstrong D, Taylor L, Gill BP, Edwards SA: The welfare of finishing pigs in two contrasting housing systems: Fully-slatted versus straw-bedded accommodation. Livest Sci 2006, 103(1-2):104-115.

49. Presto MH, Andersson HK, Folestam S, Lindberg JE: Activity behaviour and social interactions of pigs raised outdoors and indoors. Archiv Fur Tierzucht 2008, 51(4):338-350

50. Beattie VE, O'Connell NE, Moss BW: Influence of environmental enrichment on the behaviour, performance and meat quality of domestic pigs. Livest Prod Sci 2000, 65(1-2):71-79.

51. Beattie VE, Walker N, Sneddon IA: An investigation of the effect of environmental enrichment and space allowance on the behaviour and production of growing pigs. Appl Anim Behav Sci 1996, 48(3-4):151-158.

52. Van Grevenhof EM, Heuven HCM, Van Weeren PR, Bijma P: The relationship between growth and osteochondrosis in specific joints in pigs. Livest Sci 2012, 143(1):85-90.

53. Høøk-Presto M: Organic Pig Meat Production; Nutritient Supply, Behaviour and Health. PhD Thesis. Uppsala: SLU; 2008

54. McCoy AM, Toth F, Dolvik NI, Ekman S, Ellermann J, Olstad K, Ytrehus B, Carlson CS: Articular osteochondrosis: a comparison of naturallyoccurring human and animal disease. Osteoart Cartilage 2013, 21(11):1638-1647.

55. Bohndorf K: Osteochondritis (osteochondrosis) dissecans: a review and new MRI classification. Eur Radio 1998, 8(1):103-112.

56. Edmonds EW, Polousky J: A review of knowledge in osteochondritis dissecans: 123 years of minimal evolution from König to the ROCK study group. Clin Orthop Relat Res 2013, 471(4):1118-1126.

57. Potter R: Clinical conditions of pigs in outdoor breeding herds. In Practice 1998, 20(1):3-14.

58. Petersen JS, Oksberg N, Jørgensen B, Sørensen MT: Growth performance, carcass composition and leg weakness in pigs exposed to different levels of physical activity. Anim Sci 1998, 66:725-732.

59. Enfalt AC, Lundstrøm $K$, Hansson I, Karlsson A, Esséngustavsson B, Håkansson J: Moderate indoor exercise - effect on production and carcass traits, muscle enzyme activities and meat quality in pigs. Anim Sci 1993, 57:127-135.

60. Grøndalen T: Leg weakness in pigs. I. Incidence and relationship to skeletal lesions, feed level, protein and mineral supply, exercise and exterior conformation. Acta Vet Scand 1974, 15(4):555-573.

61. Ytrehus B, Haga A, Mellum CN, Mathisen L, Carlson CS, Ekman S, Teige J, Reinholt FP: Experimental ischemia of porcine growth cartilage produces lesions of osteochondrosis. Orthop Res 2004, 22(6):1201-1209.
62. Olstad K, Hendrickson EH, Carlson CS, Ekman S, Dolvik NI: Transection of vessels in epiphyseal cartilage canals leads to osteochondrosis and osteochondrosis dissecans in the femoro-patellar joint of foals, a potential model of juvenile osteochondritis dissecans. Osteoarth Cartilage 2013, 21(5):730-738.

63. Grøndalen T: Osteochondrosis and arthrosis in Norwegian slaughter pigs in 1980 compared to 1970. Nordisk Veterinaer Medicin 1981, 33(9-11):417-422.

64. Grøndalen $\mathrm{T}$, Vangen $\mathrm{O}$ : Osteochondrosis and arthrosis in pigs $\mathrm{V}$ Comparison of incidence in three different lines of the Norwegian Landrace breed. Acta Vet Scand 1974, 15(1):61-79.

65. Nakano T, Aherne FX, Brennan JJ, Thompson JR: Effect of growth rate on the incidence of osteochondrosis in growing swine. Can Anim Sci 1984, 64(1):139-146.

66. Busch ME, Wachmann H: Osteochondrosis of the elbow joint in finishing pigs from three herds: associations among different types of joint changes and between osteochondrosis and growth rate. Vet J 2011, 188(2):197-203.

67. Kold SE: The incidence and treatment of bone cysts in the equine stifle joint. Vet Annual 1986, 26:187-194.

68. Carlsten J, Sandgren B, Dalin G: Development of osteochondrosis in the tarsocrural joint and osteochondral fragments in the fetlock joints of Standardbred trotters. I. A radiological survey. Equine Vet J 1993, 25(S):42-47.

69. Grøndalen T: Osteochondrosis and arthrosis in pigs. VI. Relationship to feed level and calcium, phosphorus and protein levels in the ration. Acta Vet Scand 1974, 15(2):147-169.

70. Wallenbeck A, Rydhmer L, Lundeheim N: GxE interactions for growth and carcass leanness: Re-ranking of boars in organic and conventional pig production. Livest Sci 2009, 123(2-3):154-160.

\section{doi:10.1186/s12917-014-0208-5}

Cite this article as: Etterlin et al.: Effects of free-range and confined housing on joint health in a herd of fattening pigs. BMC Veterinary Research 2014 10:208.

\section{Submit your next manuscript to BioMed Central and take full advantage of:}

- Convenient online submission

- Thorough peer review

- No space constraints or color figure charges

- Immediate publication on acceptance

- Inclusion in PubMed, CAS, Scopus and Google Scholar

- Research which is freely available for redistribution 